\title{
Platelet Inhibition in Acute Coronary Syndrome and Percutaneous Coronary Intervention: Insights from the Past and Present
}

\author{
Diana A. Gorog ${ }^{1,2}$ Tobias Geisler ${ }^{3}$ \\ ${ }^{1}$ National Heart and Lung Institute, Imperial College, London, \\ United Kingdom \\ 2 Postgraduate Medical School, University of Hertfordshire, \\ Hertfordshire, United Kingdom \\ ${ }^{3}$ Department of Cardiology and Angiology, University Hospital, \\ Eberhard-Karls-University Tuebingen, Tuebingen, Germany
}

\begin{abstract}
Address for correspondence Diana A. Gorog, MD, PhD, FRCP, National Heart and Lung Institute, Imperial College London SW3 6LY,

United Kingdom (e-mail: d.gorog@imperial.ac.uk).
\end{abstract}

Thromb Haemost 2020;120:565-578.

\author{
Abstract \\ Keywords \\ - Acute Myocardial \\ Infarction \\ - antiplatelet agents \\ - arterial thrombosis \\ - thrombosis \\ - coagulation inhibitors
}

Platelet activation and aggregation have a pivotal role in arterial thrombosis and in the pathogenesis of both acute coronary syndromes (ACS) and in the thrombotic complications that occur in patients undergoing percutaneous coronary intervention ( $\mathrm{PCl})$. The past 30 years has seen the progress from early trials of clopidogrel and glycoprotein IIb/IIla inhibitors to the application of more potent $\mathrm{P}_{2} \mathrm{Y}_{12}$ inhibitors prasugrel and ticagrelor. Early enthusiasm for newer and more potent antiplatelet agents, which could reduce ischemic events, has led to the understanding of the importance of bleeding and a desire to individualize and optimize treatment. It has increasingly become apparent that the potency and duration of dual antiplatelet therapy (DAPT) has to reflect the balance between ischemic and bleeding risk. Recently, multiple strategies have been proposed to individualize DAPT intensity and duration to reduce the bleeding and ischemic risks. Strategies of de-escalation of DAPT intensity, as well as shorter (less than a year) or more prolonged (beyond a year) treatment have been proposed, as well as platelet function test and genotype guidance of $\mathrm{P}_{2} \mathrm{Y}_{12}$ inhibitor therapy. Herein, we provide an overview of the progress in the field of antiplatelet therapy for ACS and $\mathrm{PCl}$ over the years, showing the current directions of travel. Ongoing studies focusing on personalized antiplatelet treatment will hopefully yield further insight into ways of optimizing outcomes for the individual.

\section{Importance of Platelets in ACS and post-PCI Complications}

Platelet activation and aggregation have a pivotal role in arterial thrombosis and in the pathogenesis of both acute coronary syndromes (ACS) and in the thrombotic complications that occur in patients undergoing percutaneous coronary intervention (PCI). In the 1980s, postmortem studies showed that in the majority of patients who died from sudden death due to ischemic heart disease, plaque disruption with overlying thrombus formation was responsible for the fatal acute myocardial infarction (AMI). ${ }^{1,2}$ In most cases, the presentation of an ACS is attributable to acute changes in a coronary atheroma, with resultant platelet thrombus formation, which can result in downstream macro- or microinfarction. Furthermore, thrombi are frequently observed at sites other than those of the major culprit lesion in patients with ACS. $^{1}$ The appreciation that thrombi in patients with ACS are predominantly formed of platelets ${ }^{2}$ led to an increased search for antiplatelet therapy to treat and prevent coronary thrombosis. received

September 7, 2019

accepted after revision

January 9, 2020
(C) 2020 Georg Thieme Verlag KG Stuttgart . New York
DOI https://doi.org/ 10.1055/s-0040-1702920. ISSN 0340-6245. 


\section{Balancing the Risk of Thrombosis against the Risk of Bleeding}

Antiplatelet therapy, while reducing thrombosis, also increases bleeding risk. For patients with ACS, there is a strong relationship between bleeding, mortality, and AMI. Major bleeding significantly increases the risk of death ${ }^{3,4}$ and AMI. ${ }^{4}$ Bleeding often leads to attenuation or cessation of antithrombotic therapy, thus enhancing the thrombotic risk.

Since both thrombotic and bleeding risks vary from one individual to the next, the benefits and risks of DAPT should be considered when deciding on the intensity and duration of DAPT. There is often a fine balance between benefit and risk, such that decisions on antiplatelet strategy should incorporate an assessment of both ischemic and bleeding risks, with respect to both the intensity and the duration of DAPT. Risk scores can be helpful to guide DAPT treatment, and include the DAPT, ${ }^{5}$ the PRECISE-DAPT (PREdicting bleeding Complications In patients undergoing Stent implantation and subsEquent Dual Anti Platelet Therapy), ${ }^{6}$ and the PARIS (Patterns of nonAdherence to antiplatelet Regimen in Stented patients) scores. ${ }^{7}$ However, their use is somewhat limited, and prospective trials have not validated the safety of using these scores to guide DAPT duration. In addition, there is a large overlap between bleeding and thrombotic risk factors in traditional scores, thus preventing a reasonable evaluation of the net benefit. More recently, the Academic Research Consortium for High-Bleeding Risk has proposed a new definition of highbleeding risk to provide consistency in clinical trials evaluating the safety and effectiveness of devices and drug regimens for patients undergoing $\mathrm{PCI}$, defined as $\geq 4 \%$ risk of Bleeding Academic Research Consortium (BARC) 3 to 5 bleeding or a $\geq 1 \%$ risk of intracranial hemorrhage at 1 year. $^{8}$

\section{Early Antithrombotic Therapy}

In 1988, the landmark Second International Study of Infarct Survival trial in 17,187 patients with suspected AMI showed unequivocally that for every 1,000 patients, treatment with aspirin led to a reduction of approximately 25 deaths and 10 to 15 nonfatal reinfarctions or strokes during the first month and that the benefits of early treatment with aspirin were largely independent of, and additive to, those of fibrinolytic therapy (- Table 1). ${ }^{9}$ The Antithrombotic Trialists' Collaboration metaanalysis involving 287 studies established that antiplatelet therapy-primarily with aspirin-reduces the incidence of death, AMI, or stroke in patients at high-vascular risk by $25 \%{ }^{10}$ Aspirin became first-line therapy for all patients with cardiovascular disease, including ACS and those undergoing $\mathrm{PCI}$, and remains so in current guidelines. ${ }^{11,12}$ The mechanism of action of aspirin and other antiplatelet medications is shown in -Fig. 1.

\section{P2Y 12 Inhibitors}

The CURE trial in 2001 showed that the addition of clopidogrel to aspirin in patients with ACS reduced major adverse cardiovascular events (MACE) by $20 \%$ compared with aspirin alone in patients suffering from non-ST elevation ACS (-Table 1 and -Fig. 2). ${ }^{13}$ Subsequent studies showed that dual antiplatelet therapy (DAPT) comprising of clopidogrel and aspirin reduced MACE after PCI in both stable angina and ACS patients when compared with aspirin alone. ${ }^{14}$

The antiplatelet effect of clopidogrel is relatively modest, however, taking up to 8 hours to achieve maximal effect and did not fully eliminate the recurrent ischemic events post-AMI. Subsequent generations of $\mathrm{P}_{2} \mathrm{Y}_{12}$ receptor inhibitors prasugrel (a third-generation thienopyridine) and ticagrelor (a nonthienopyridine $\mathrm{P}_{2} \mathrm{Y}_{12}$ inhibitor) both achieve more rapid and significantly higher levels of platelet inhibition compared with clopidogrel. ${ }^{15,16}$ Subsequently, the Trial to Assess Improvement in Therapeutic Outcomes by Optimizing Platelet Inhibition with Prasugrel-Thrombolysis in Myocardial Infarction (TRITON-TIMI) 38, and the study of Platelet Inhibition and Patient Outcomes studies demonstrated that prasugrel and ticagrelor, respectively, were superior to clopidogrel in terms of reducing ischemic events, albeit with a higher risk of bleeding. ${ }^{15-17}$ Subsequent studies, including a subgroup analysis of patients from the Platelet Inhibition and Patient Outcomes trial who were treated with primary $\mathrm{PCI}(\mathrm{PPCI})$ revealed that stent thrombosis occurred significantly less often in ticagrelor than in clopidogrel-treated patients ${ }^{18}$ demonstrating the importance of platelet inhibition in also preventing stent thrombosis. Prasugrel and ticagrelor have therefore become first-line treatment in ACS, ${ }^{11,12}$ and for many years have been used largely interchangeably assuming similar effectiveness in the absence of head-to-head trials. A very recent head-to-head comparison of prasugrel and ticagrelor in the ISAR-REACT 5 study, demonstrated that in patients with ACS, treatment with prasugrel significantly reduced the risk of the composite of death, myocardial infarction or stroke compared with ticagrelor, without an increase in major bleeding. ${ }^{19}$ This highlights the risks associated with assuming similar efficacy of treatments based on pharmacodynamic data and trials of individual drugs in similar patient cohorts, that may be misleading in the absence of direct comparison, which is essential to determine the true comparative effectiveness of medications.

\section{Glycoprotein IIb/IIla Inhibitors}

The final common pathway of platelet aggregation involves the binding of fibrinogen to adjacent platelets by means of glycoprotein IIb/IIIa integrin on the platelet surface. The role of suboptimal platelet inhibition at the time of PCI as a contributor to early stent thrombosis post-PCI is well recognized. Potent intravenous glycoprotein IIb/IIIa inhibitors (GPI) abciximab, tirofiban, and eptifibatide have all been shown to reduce the incidence of death and recurrent AMI in high-risk patients undergoing PCI compared with unfractionated heparin alone, particularly in the setting the ACS. ${ }^{20-22}$ Importantly, this reduction in events was mainly driven by a reduction in periprocedural myocardial infarction.

A large-scale meta-analysis of 221,066 patients with 4,276 episodes of stent thrombosis, reported that early DAPT discontinuation was one of the most important predictors of stent thrombosis. ${ }^{23}$ The role of potent platelet 


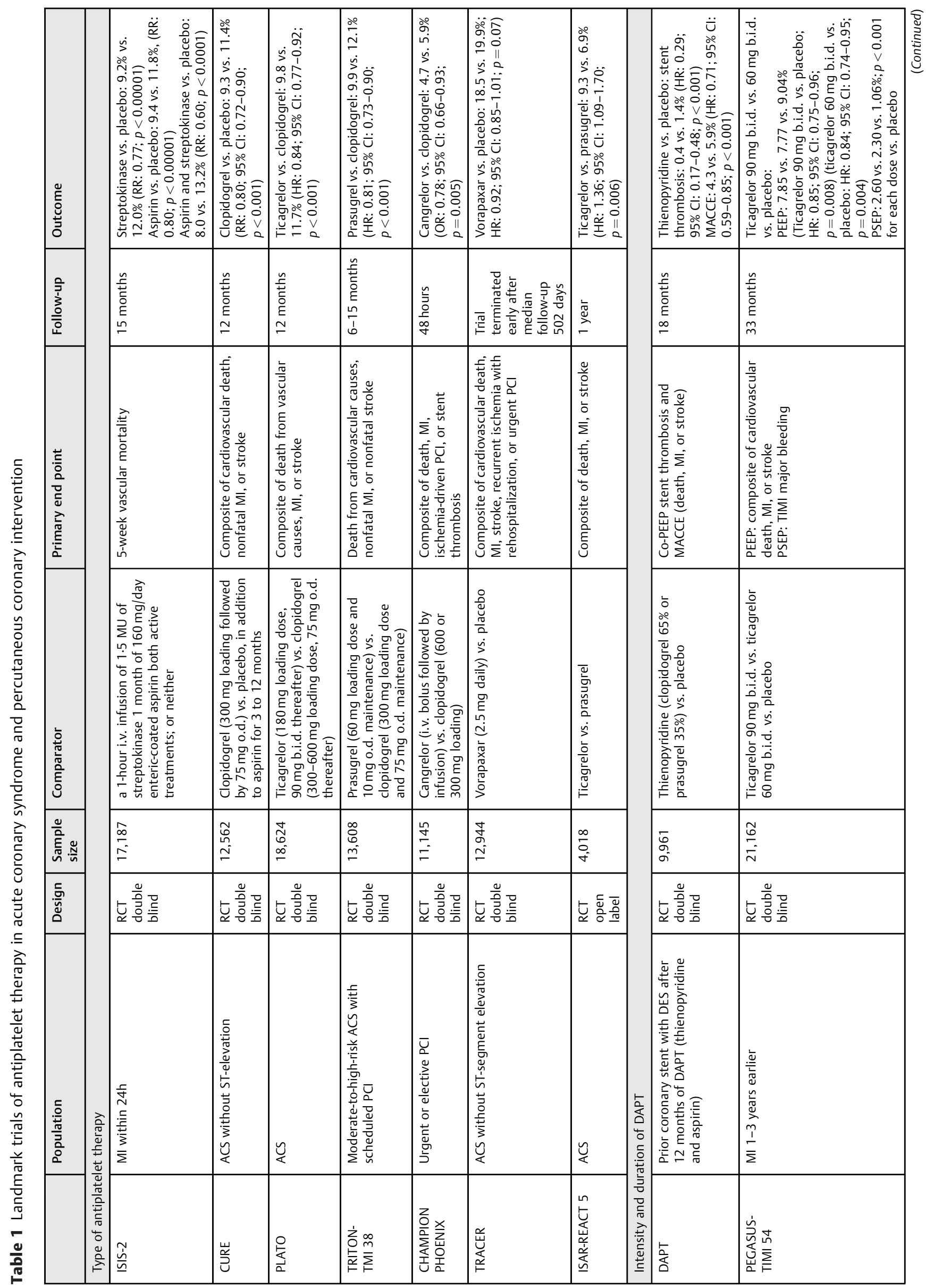




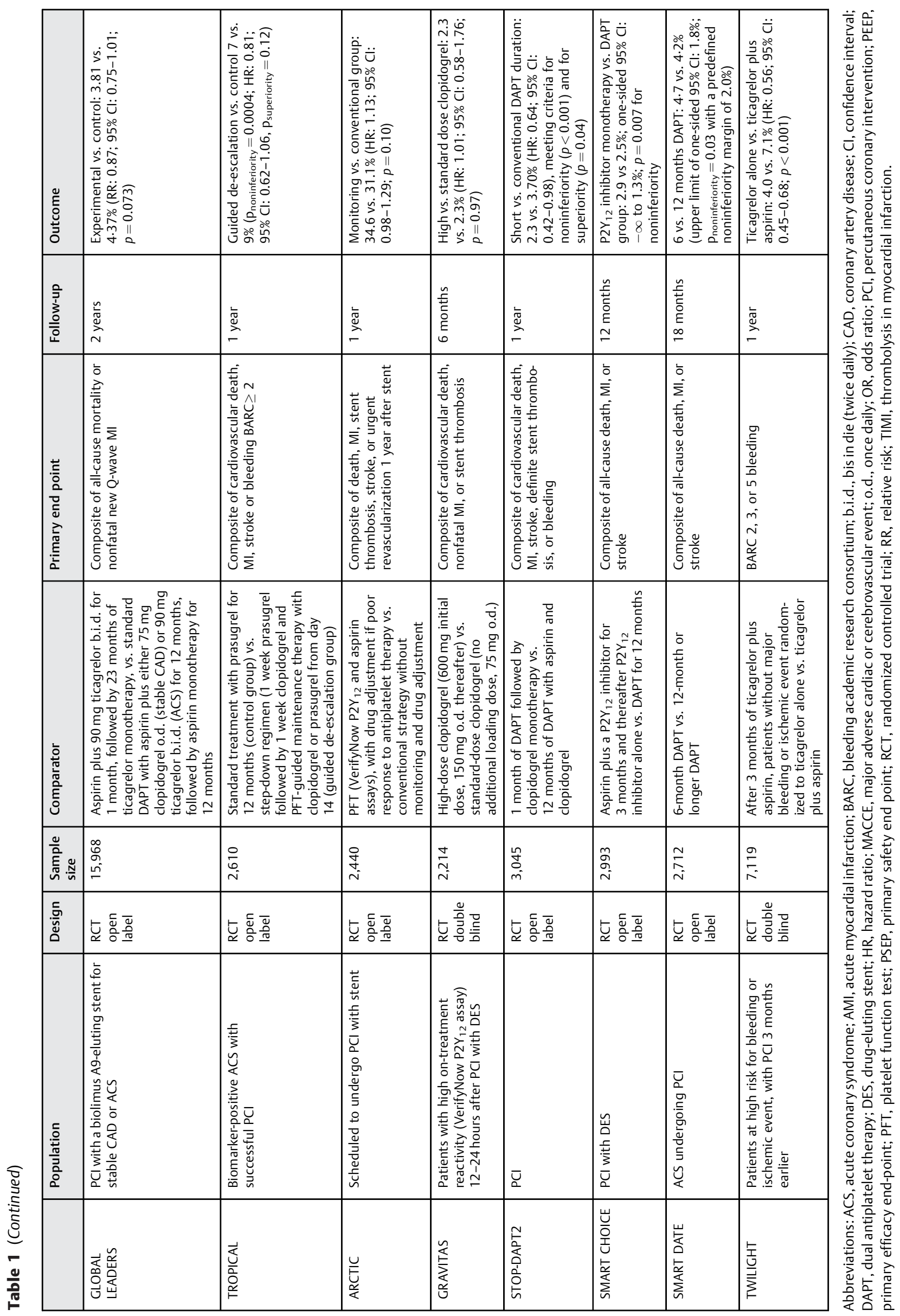




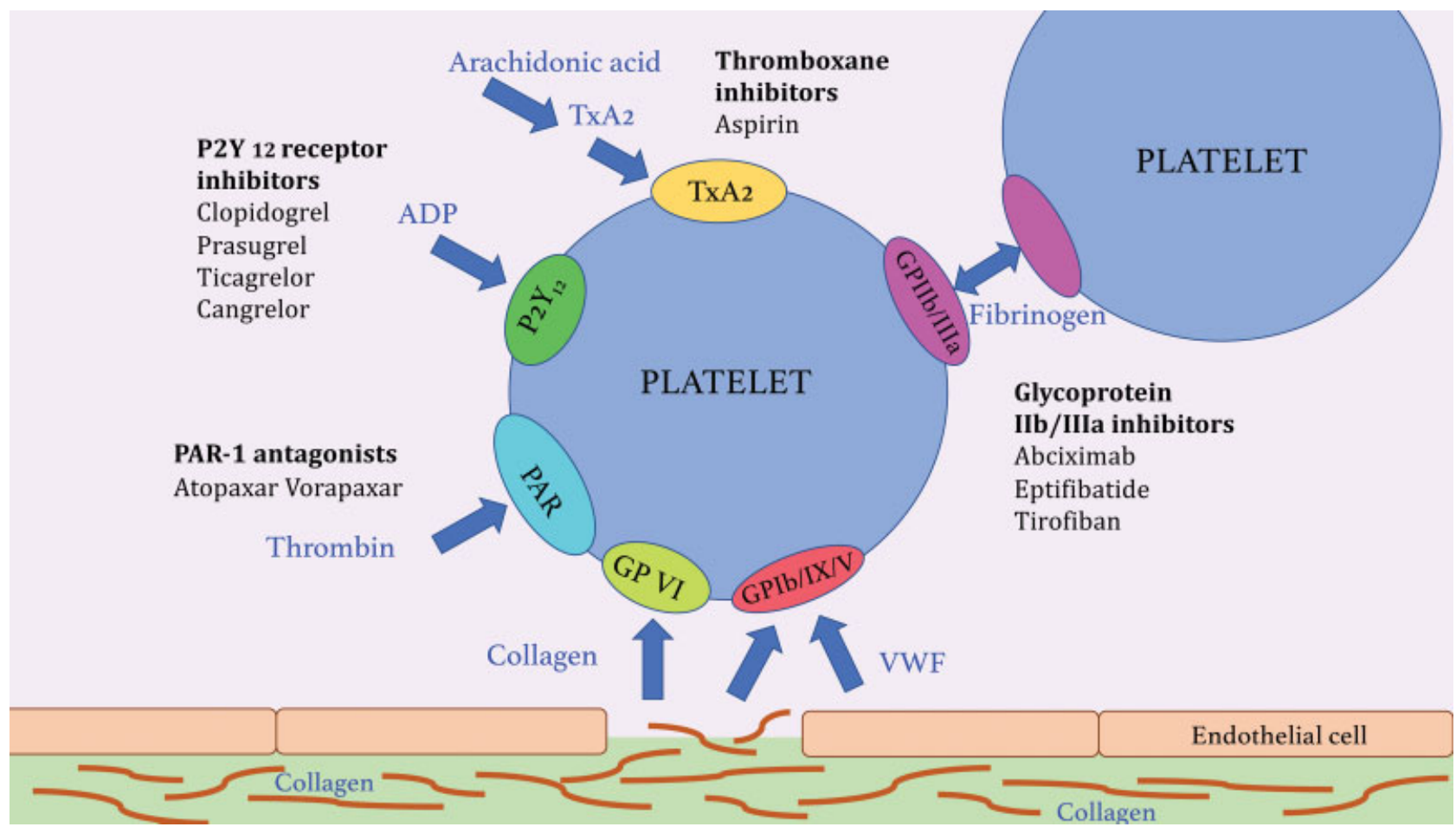

Fig. 1 Mechanism of action of antiplatelet medications. ADP, adenosine diphosphate; GP, glycoprotein; PAR, protease-activated receptor; TxA2, thromboxane A2; VWF, von Willebrand factor.

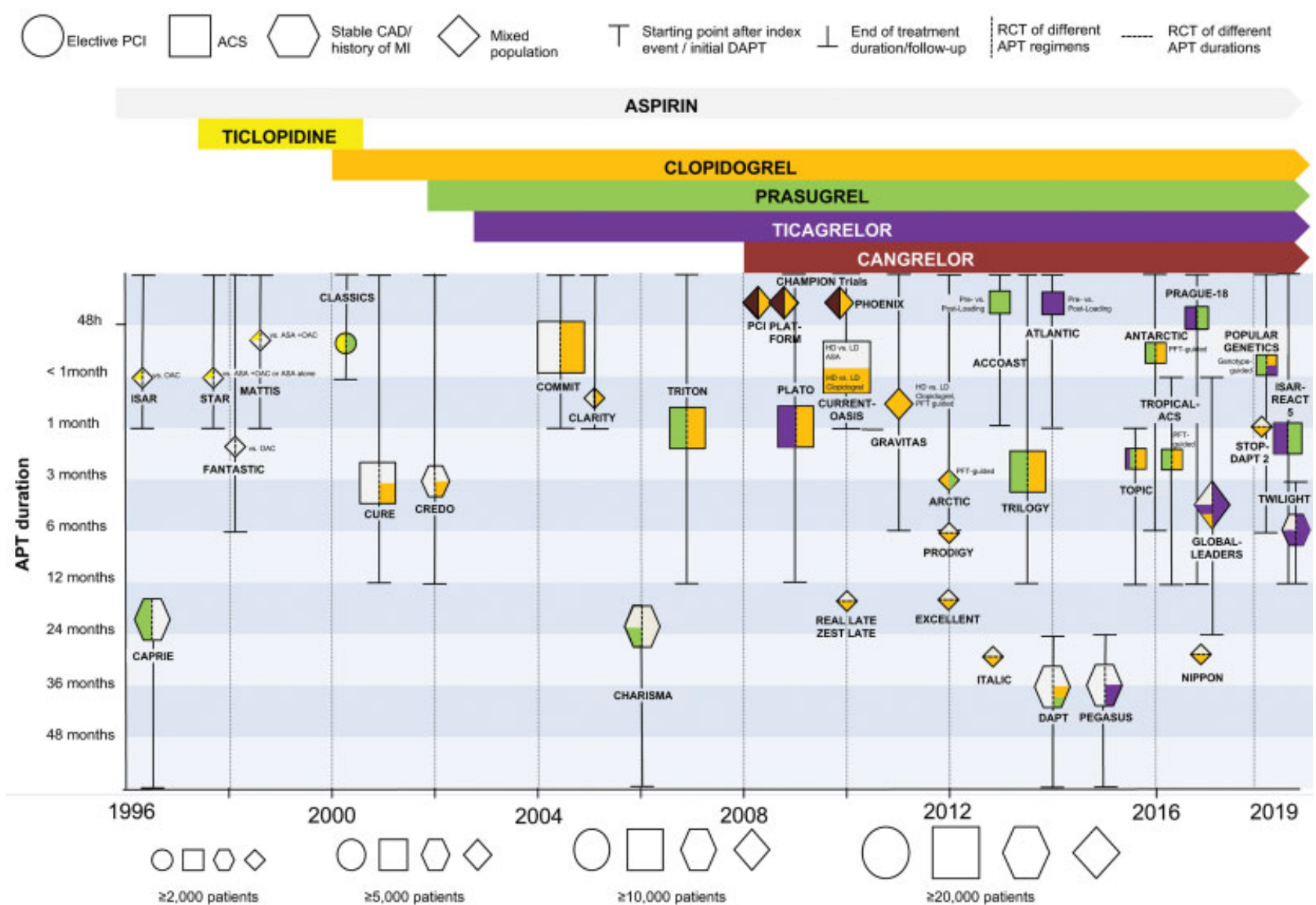

Fig. 2 Evolution of antiplatelet secondary prevention (aspirin plus $\mathrm{P}_{2} \mathrm{Y}_{12}$ inhibitor) trials in acute coronary syndrome and percutaneous coronary intervention. 
inhibition in reducing stent thrombosis is further supported by the observation that GPI treatment in ACS reduces acute stent thrombosis compared with heparin alone. ${ }^{24,25}$ Although met with initial enthusiasm, GPI significantly increased the risk of bleeding and have not been shown to have net clinical benefit in low-risk ACS or stable coronary disease patients. The appreciation of the risk of bleeding impacting on mortality has led to a significant reduction in GPI use, but these drugs continue to have a role in high-risk ACS patients undergoing PCI.

\section{Importance of High on Treatment Platelet Reactivity}

The desire to avoid recurrent ischemic events which occurred in some patients despite DAPT led to studies to try and identify "nonresponders" to clopidogrel. ${ }^{26,27}$ In ACS patients treated with PCI and DAPT including clopidogrel, persistent high on-treatment platelet reactivity (HTPR) to adenosine diphosphate was shown to be associated with a significant increase in nonfatal myocardial infarction, stent thrombosis, and cardiovascular mortality. ${ }^{28-34}$

Furthermore, 20 to $30 \%$ of patients with ACS show an inadequate response to clopidogrel, depending on the platelet function test used. ${ }^{35}$ Some 5 to $12 \%$ of the variation of adenosine diphosphate-induced platelet aggregation is related to genetic polymorphisms encoding CYP2C19, the hepatic enzyme responsible for biotransformation of clopidogrel to its active metabolite. ${ }^{36}$ The CYP2C19 618G $>A^{*} 2$ allele-carried by approximately $30 \%$ of Caucasians and $50 \%$ of East Asians ${ }^{35}$ is the most common polymorphism, resulting in loss of function (LoF) of CYP2C19 enzyme activity. Homozygotes for the CYP2C19*2 and less common CYP2C19*3 LoF alleles are poor metabolizers, and heterozygotes are intermediate metabolizers of clopidogrel. These individuals have high-on clopidogrel platelet reactivity and an increased risk of adverse cardiovascular events-including an increased risk of AMI and stent thrombosis-particularly post-PCI. ${ }^{37}$ In the FAST-MI registry, among 2,208 patients receiving clopidogrel-those carrying two CYP2C19 LoF alleles $\left({ }^{*} 2,{ }^{*} 3,{ }^{*} 4\right.$, or $\left.{ }^{*} 5\right)$-experienced a twofold increase in cardiovascular events compared with those without LoF alleles, an effect most marked among those undergoing $\mathrm{PCI}^{38}$ In a meta-analysis involving 9,685 patients (91\% undergoing $\mathrm{PCI}$ and $55 \%$ with ACS), those carrying one or two CYP2C19*2 alleles had increased rates of cardiovascular events compared with noncarriers and an increased risk of stent thrombosis. ${ }^{39}$ Consequently, in 2010, the US Food and Drug Administration announced a boxed warning on clopidogrel stating that the drug has a reduced effect in patients based on their CYP2C19 genotype. A meta-analysis assessing 32 studies involving 42,016 patients concluded that although there was an association between the CYP2C19 genotype and clopidogrel responsiveness, there was no significant association of genotype with cardiovascular events. ${ }^{40}$ However, a subsequent meta-analysis showed that the association of CYP2C19 genotype with adverse cardiovascular outcomes in whites was restricted to those undergoing $\mathrm{PCI}$, and conferred a greater risk in Asians undergoing PCI. ${ }^{41}$ By contrast, the CYP2C19*17 gain- of-function allele appears to confer enhanced response to clopidogrel and increased bleeding risk. ${ }^{40,42}$

\section{Individualized Antiplatelet Therapy}

Prasugrel and ticagrelor are not affected by CYP polymorphisms, and these agents can eliminate the HTPR seen with clopidogrel in $\mathrm{CYP} \mathrm{C}_{19}{ }^{*} 2$ allele carriers. ${ }^{43,44}$ There is no evidence that escalating antiplatelet therapy based on CYP2C19 genotyping results in an improvement in clinical outcome and reduction in cardiovascular events. However, the very recently published POPular Genetics study showed that in patients with ST-elevation myocardial infarction (STEMI) undergoing PPCI, a genotype-guided de-escalation from prasugrel/ticagrelor to clopidogrel in those who are not CYP2C $19^{*} 2$ or $3^{*}$ allele carriers results in a reduction in bleeding without an increase in thrombosis risk. ${ }^{45}$

Studies were also conducted to assess the impact of overcoming HTPR on cardiovascular outcomes. In patients undergoing elective PCI with HTPR on clopidogrel, doubling the dose of clopidogrel in the Gauging Responsiveness with a VerifyNowAssay-Impact on Thrombosis and Safety (GRAVITAS) trial $^{46}$ or switching from clopidogrel to prasugrel in the Testing Platelet Reactivity In Patients Undergoing Elective Stent Placement on Clopidogrel to Guide Alternative Therapy With Prasugrel (TRIGGER-PCI) trial ${ }^{47}$ failed to translate into an improvement in clinical outcome. Among patients undergoing PCI for stable coronary artery disease or non-ST elevation ACS, intensification of antiplatelet therapy based on the results of the VerifyNow assay by increasing the dose of aspirin, clopidogrel, or switching to prasugrel, or by additional treatment with GPI in the ARCTIC trial, ${ }^{48}$ or using prasugrel or clopidogrel in elderly patients with ACS in the ANTARCTIC trial ${ }^{49}$ failed to reduce the occurrence of adverse cardiovascular events. Thus, we now know that increasing the dose of clopidogrel or using more potent antiplatelet medications can reduce platelet reactivity and overcome HTPR on clopidogrel, but that this does not translate into an improvement in clinical outcomes in low-medium risk patients. ${ }^{27,50}$

However, it is possible that these neutral results may be explained by trial designs that could not have shown the effectiveness of platelet function-guided $\mathrm{P}_{2} \mathrm{Y}_{12}$ inhibitor intensification. The GRAVITAS and the TRIGGER PCI trials enrolled low-risk patients in whom the observed MACE rate was so small that a difference in outcome could not be detected given the relative sample size, while in the ANTARCTIC trial of higher risk elderly ACS patients, intensification of $\mathrm{P}_{2} \mathrm{Y}_{12}$ inhibitor treatment was only applied to $4 \%$ of patients.

Furthermore, regardless of genotyping or testing for platelet reactivity, the use of ticagrelor or prasugrel is recommended over the use clopidogrel in patients with ACS. ${ }^{11,12}$

Whether assessment of platelet reactivity or genotyping should be performed, remains unclear. Assessment of on-treatment platelet reactivity may be useful to identify high-risk individuals, but does not lead to useful information in terms of altering treatments and cannot be recommended in routine clinical practice. Benefits of genotyping include (1) the ability to use clopidogrel without fear of a higher risk of acute ischemic 
events, especially stent thrombosis, in patients who carry two loss-of-function alleles, and potentially more widespread clopidogrel prescribing, which could lead to (2) reduced bleeding complications in these patients compared with the use of newer $\mathrm{P}_{2} \mathrm{Y}_{12}$ inhibitors, and (3) reduced prescribing costs since clopidogrel is cheaper than the newer $\mathrm{P} \mathrm{Y}_{12}$ inhibitors. However, the negative aspects of routine screening include the fact that (1) the majority of ACS patients are now treated with prasugrel and ticagrelor because of their greater efficacy in reducing ischemic events, (2) genotyping is costly, and (3) there are logistic difficulties with implementing genotyping in a timely manner, for example, point-of-care testing, (4) a large number of patients would have to be screened to identify a relatively small cohort who would benefit, and (5) the cost savings associated with cheaper prescribing costs of clopidogrel, in comparison to newer $\mathrm{P}^{2} \mathrm{Y}_{12}$ inhibitors, would almost certainly be offset by the costs of genotyping (both testing costs and manpower).

\section{Speed and Intensity of Platelet Inhibition}

The speed of onset and intensity of platelet inhibition during $\mathrm{PCI}$ is an important determinant of PCI-related ischemic complications, and this is particularly relevant in ACS, especially STEMI. ${ }^{33,51}$ However, the onset of action of oral P2Y 12 receptor inhibitors is attenuated in STEMI patients due to delayed absorption. ${ }^{51}$ Crushing P2Y $_{12}$ inhibitor tablets has been shown to provide more rapid platelet inhibition than standard oral dosing. Chewed ticagrelor tablets may also result in a similar effect.

The intravenous $\mathrm{P}_{2} \mathrm{Y}_{12}$ inhibitor cangrelor has almost immediate onset of effect, is rapidly reversible and could provide the "bridging" antiplatelet effect required before the onset of effect of oral P2 $\mathrm{Y}_{12}$ inhibitors. In the CHAMPION PHOENIX trial ${ }^{52}$ in 11,145 patients undergoing $\mathrm{PCI}$ for the spectrum of coronary disease presentations (STEMI, non-STsegment elevation ACS, or stable angina) randomized to cangrelor or placebo, in addition to DAPT (aspirin and clopidogrel), showed that cangrelor significantly reduced the rate of ischemic events, including stent thrombosis during PCI without significant increase in severe bleeding. This may be particularly relevant in patients with cardiogenic shock, which is associated with delayed absorption of orally administered $\mathrm{P}_{2} \mathrm{Y}_{12}$ inhibitors ${ }^{53}$

\section{Opioid and Oral P2Y 12 Inhibitor Interaction}

In the last few years, concerns have arisen about a possible negative pharmacodynamic interaction between opiates, such as morphine and fentanyl, used for the relief of chest pain in AMI and oral P2Y $\mathrm{Y}_{12}$ inhibitors. ${ }^{54-57}$ Several studies have shown that opioids delay the onset of effect and reduce the maximal platelet inhibition achieved by oral $\mathrm{P}_{2} \mathrm{Y}_{12}$ inhibitors ${ }^{54,58-60}$ through delay in gastrointestinal absorption. ${ }^{61}$ In patients with stable coronary disease, morphine but not saline, was shown to significantly delay prasugrel absorption and the onset of platelet inhibition. ${ }^{62}$ However, the clinical sequalae of this pharmacodynamic interaction is less clear, with no available prospective randomized trials assessing the impact of opioids in ACS on hard clinical endpoints. Small observational studies show varying impact on adverse cardiovascular events such as death and reinfarction ${ }^{63-65}$ with a signal for increased events and larger infarct size with opiate use. ${ }^{66}$ An observational study in patients with anterior STEMI showed a trend toward higher reinfarction rate in patients receiving morphine compared with those not receiving morphine, ${ }^{67}$ while in the ATLANTICMorphine study, STEMI patients treated with ticagrelor and concomitant morphine had reduced pre-PPCI epicardial flow were more frequently given GPI and more frequently underwent thrombus aspiration, indicating larger thrombus burden than patients not receiving morphine. ${ }^{68} \mathrm{~A}$ recent meta-analysis indicates that STEMI patients treated with morphine may have a higher rate of early reinfarction compared with those treated without morphine. ${ }^{69}$ The European Society of Cardiology downgraded the level of evidence for the use of intravenous opioids in the setting of STEMI from level I to level IIa. ${ }^{11}$

Options to overcome the opioid-P2 $\mathrm{Y}_{12}$ inhibitor interaction include the use of nonopioid analgesics such as intravenous paracetamol. If opioids are used, coadministration of metoclopramide can enhance ticagrelor absorption and platelet inhibition compared with morphine treatment alone. ${ }^{70}$ Oral $\mathrm{P} \mathrm{Y}_{12}$ inhibitor absorption can also be improved by giving crushed ticagrelor or prasugrel through a nasogastric tube $^{71-73}$ or using orodispersible ticagrelor. ${ }^{70}$ Concomitant platelet inhibition can be achieved until oral medications can reach maximal effect through the use of cangrelor ${ }^{74,75}$ or GPI. ${ }^{74,75}$

\section{More Intensive or Prolonged Antiplatelet Therapy}

Following concerns of late stent thrombosis associated with drug-eluting stent (DES) implantation in the late 2000s, prolonged DAPT treatment became recommended following PCI with DES for a minimum of 12 months. In current clinical practice, the default strategy in most centers is 12 -months DAPT followed by aspirin for life. The effect of more prolonged DAPT, beyond 1 year, in patients with ACS was assessed in the PEGASUS TIMI 54 study. ${ }^{76}$ In 21,162 patients with prior AMI randomized to ticagrelor $90 \mathrm{mg}$ twice daily, $60 \mathrm{mg}$ twice daily, or placebo; in addition to aspirin, the use of ticagrelor $60 \mathrm{mg}$ twice daily significantly reduced the occurrence of the composite of cardiovascular death, AMI, or stroke compared with placebo at the expense of increased major bleeding. ${ }^{76}$ More recently, the GLOBAL LEADERS study showed that DAPT for 1 month followed by ticagrelor monotherapy for 23 months was not superior to 12 months of DAPT, followed by 12 months of aspirin monotherapy with regards to mortality, ischemic, or bleeding complications. ${ }^{77}$

\section{Less Intensive or Shorter Antiplatelet Therapy}

The observation that ticagrelor and prasugrel significantly reduce ischemic events, but increase bleeding risk in ACS patients undergoing $\mathrm{PCl}$ led to studies to assess shortened or 
less intensive DAPT regimens to achieve sufficient platelet inhibition with an acceptable bleeding risk.

Following DES implantation, several studies have assessed the shorter DAPT regimens ( $\leq 3$ months) and showed these to be noninferior to the traditional 12-month regimen with regard to the occurrence of ischemic events. ${ }^{78-81}$ A very recent systematic review and network meta-analysis-including 17 studies and 46,864 patients-concluded that compared with short-term DAPT using clopidogrel, long-term DAPT led to higher rates of major bleeding and noncardiac death, and conventional term DAPT was associated with an increased risk of any bleeding. For patients with ACS, short-term DAPT was shown to have similar efficacy and safety as standard term DAPT $^{82}$

The effect of reducing the intensity of antiplatelet medication in ACS patients undergoing $\mathrm{PCI}$ was also assessed. The TOPIC trial of 646 patients with ACS evaluated the clinical benefit of unguided DAPT de-escalation by switching from prasugrel or ticagrelor to clopidogrel 1 month after PCI for ACS. The primary end point of cardiovascular death, urgent revascularization, stroke, and bleeding occurred half as often in the switched group as in the unswitched group, with the benefit driven by a reduction in bleeding events. ${ }^{83}$ The TROPICAL-ACS trial in 2,610 patients with ACS undergoing PCI showed that platelet function test-guided early de-escalation of antiplatelet therapy was noninferior to standard prasugrel therapy with similar rates of ischemic events including cardiovascular death, AMI or stroke and a trend toward less bleeding during guided treatment. ${ }^{84}$ However, in a prespecified subanalysis according to diabetic status showed that de-escalation in patients with diabetes was associated with nonsignificant, but numerically higher rate of the net clinical end point (composite of cardiovascular death, myocardial infarction, stroke, or BARC $\geq 2$ bleeding) than standard of care, with no observed reduction in bleeding. ${ }^{85}$ In a small substudy of TROPICAL-ACS, ${ }^{86}$ in which 603 patients were genotyped for CYP2C19*2, ${ }^{*} 3$, and ${ }^{*} 17$ alleles, the CYP2C19* 2 and CYP2C19* 17 carrier status correlated with platelet reactivity in patients treated with clopidogrel but not, as expected, in those treated prasugrel, and was proposed as a way of identifying patients who may not be suitable for de-escalation of intensive antiplatelet treatment. ${ }^{86}$ The ANTARCTIC trial in 877 ACS patients $\geq 75$ years showed similar ischemic and bleeding rates with low dose prasugrel $(5 \mathrm{mg} / \mathrm{d})$, or with platelet function-guided prasugrel dose escalation (10 $\mathrm{mg}$ prasugrel) or de-escalation ( $75 \mathrm{mg}$ clopidogrel).$^{49}$ Thus, in comparison to trials of platelet function-guided intensification of antiplatelet therapy whose results were largely neutral, trials of personalized de-escalation of $\mathrm{P}_{2} \mathrm{Y}_{12}$ inhibitor intensity appear to show promising results. In the STOP DAPT-2 trial, 3,045 patients undergoing PCI (38\% with ACS) were randomized either to 1 month of DAPT followed by clopidogrel monotherapy or to 12 months of DAPT with aspirin and clopidogrel. ${ }^{87}$ Compared with patients receiving 12 months of DAPT, patients assigned to 1 month of DAPT had a significantly lower rate of the composite of cardiovascular death, AMI, ischemic or hemorrhagic stroke, definite stent thrombosis, or major or minor bleeding at 12 months, meeting criteria for both noninferiority and supe- riority. The SMART-CHOICE trial ${ }^{88}$ in which 2,993 patients undergoing PCI were randomized to aspirin plus a $\mathrm{P}_{2} \mathrm{Y}_{12}$ inhibitor for 3 months and thereafter $\mathrm{P}_{2} \mathrm{Y}_{12}$ inhibitor alone or DAPT for 12 months showed that $\mathrm{P}_{2} \mathrm{Y}_{12}$ inhibitor monotherapy after 3 months of DAPT was noninferior to prolonged DAPT with regards to major adverse cardiac and cerebrovascular events at 1 year. However, concerns have also emerged about shorter DAPT duration from the SMART-DATE noninferiority trial conducted in South Korea, in which 2,712 patients with ACS undergoing PCI were randomized to 6-month or 12-month or longer open-label DAPT, predominantly with clopidogrel. ${ }^{89}$ While bleeding was similar in the two arms, the primary endpoint of the composite of all-cause death, myocardial infarction, or stroke at 18 months occurred more often in 6-month than in the 12-month or longer DAPT group $\left(p_{\text {noninferiority }}=0.03\right)$ driven by more frequent myocardial infarction, indicating that short-term DAPT may not be a safe option in these patients, particularly if clopidogrel is used.

The recently published POPular AGE trial randomized patients aged 70 years or older to clopidogrel or prasugrel/ticagrelor, clopidogrel use was associated with significantly less bleeding without a signal for increase in ischemic events. ${ }^{90}$

The most recent publication in this area was the TWILIGHT study, in which more than 7,000 patients at high risk for bleeding or an ischemic event undergoing PCI were given 3 months DAPT with ticagrelor plus aspirin, and thereafter randomized to aspirin or placebo for 1 year. ${ }^{91}$ Compared with ongoing DAPT, ticagrelor monotherapy was associated with significantly lower occurrence of the primary end point of BARC type II to V bleeding. Although there was no observed increase in the risk of death, myocardial infarction, or stroke with monotherapy, the trial was underpowered to detect differences in the risk stent thrombosis and stroke.

There is, therefore, significant momentum to now not only reduce ischemic risk, but also bleeding risk in patients undergoing PCI, including for ACS, by reducing the intensity and duration of antiplatelet therapy where possible. However, it is important to note that most of the studies assessing deescalation were generally underpowered to reliably assess the safety of de-escalation on hard clinical end points, in particular myocardial infarction and stent thrombosis and the jury remains out regarding the safety of less intense or shorter duration of antiplatelet therapy for the majority of patients. It is possible that personalized therapy using genotyping or phenotyping with platelet function testing to assess the potential effectiveness of $\mathrm{P}_{2} \mathrm{Y}_{12}$ inhibitor treatment may allow de-escalation of antiplatelet therapy intensity to reduce bleeding while avoiding ischemic events. Apart from the logistic challenges of genotyping ACS patients in a timely manner, this concept is really only applicable to clopidogrel treatment and assessment of platelet reactivity is more generalizable to all $\mathrm{P}^{2} \mathrm{Y}_{12}$ inhibitors, including those currently in development (vide infra) and also more practicable. Furthermore, theoretically, effective platelet inhibition may negate the need for genotyping to assess drug effectiveness. Future large trials would be required to assess the safety and efficacy of such personalized approaches. 


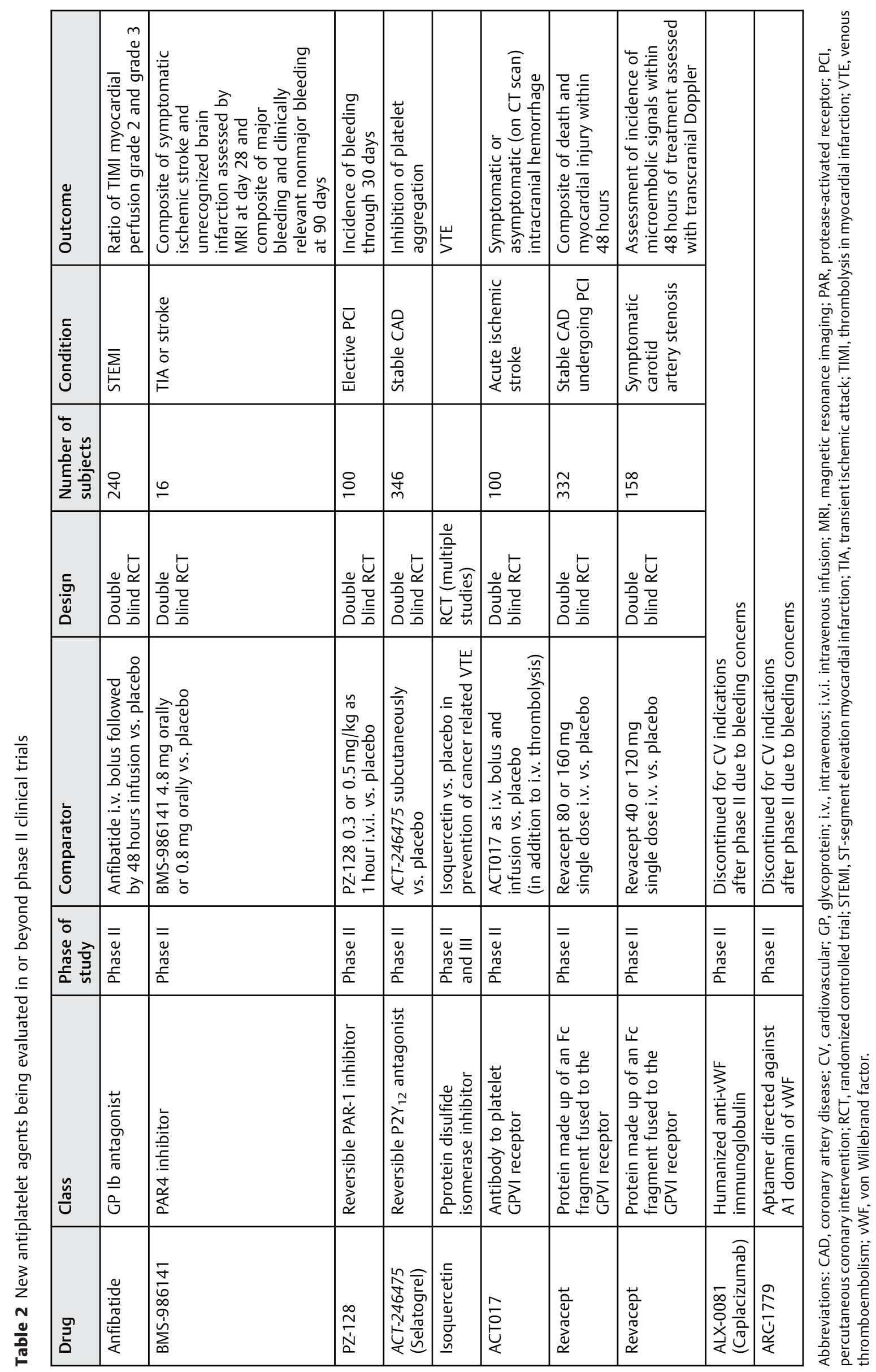




\section{Novel Therapeutic Targets}

\section{Novel $\mathrm{P}_{2} \mathrm{Y}_{12}$ and $\mathrm{P}_{2} \mathrm{Y}_{1}$ Inhibitors}

Novel P2Y 12 inhibitors include selatogrel, AZD1283, and SAR216471 (- Table 2). ${ }^{92,93}$ Recently, in a phase II study, selatogrel was shown to provide rapid onset of potent, consistent platelet inhibition when given by subcutaneous injection. ${ }^{93}$ In animal models, the platelet $\mathrm{P}_{2} \mathrm{Y}_{1}$ inhibitor BMS-884775 demonstrated similar efficacy to clopidogrel with less bleeding. ${ }^{94}$ The combined $\mathrm{P}_{2} \mathrm{Y}_{12}$ and $\mathrm{P} 2 \mathrm{Y}_{1}$ receptor antagonist GLS-409 appears to be a highly potent antithrombotic agent in an animal model, with minimal increase in bleeding time. ${ }^{95}$

\section{Novel GP IIb/IIla Inhibitors}

Currently, available GP IIb/IIIa inhibitors block all circulating platelets, and therefore significantly increase bleeding. RUC4 , a novel small-molecule in development, is a potent antithrombotic agent which can be given by intramuscular injection, but its bleeding profile is unknown. ${ }^{96}$ Conformationspecific targeting of GP IIb/IIIa, whereby only activated GP IIb/IIIa is inhibited, results in potent antithrombotic effects without increase in bleeding in preclinical models. ${ }^{97}$ A novel approach targeting the GP IIb/IIIa integrin "outside-in" signaling, which normally triggers an intracellular signaling cascade resulting in granule secretion and clot retraction, has been shown in animal models to prevent occlusive thrombus formation without affecting hemostasis. ${ }^{98}$

\section{GPIb-vWF axis Inhibitors}

The GP Ib-IX-V complex binds to vWF via its GP Ib subunit at sites of vascular injury and under conditions of high-shear stress. Although inhibitors of the GP Ib-vWF axis exhibit antithrombotic effects, development of two anti-vWF agents (an aptamer, ARC1779 and a single-domain antibody, caplacizumab) was halted due to bleeding concerns. ${ }^{99,100}$ Anfibatide is a GP Ib antagonist that also inhibits vWF. Anfibatide has been shown to inhibit platelet adhesion and aggregation in a mouse model ${ }^{101}$ and a phase II clinical trial in patients with STEMI is underway (http://www.clinicaltrials.gov. Unique identifier: NCT02495012).

\section{Phosphatidylinositol 3 Kinase B Inhibitors}

AZD6482 is an intravenous inhibitor of the lipid kinase $\mathrm{PI} 3 \mathrm{~K} \beta$, important in signaling downstream of platelet receptors and mediating platelet adhesion under shear stress. In normal volunteers, AZD6482 exhibited mild antiplatelet effect but inhibited platelet aggregation under shear-stress, with only mild prolongation of bleeding time, but with frequent epistaxis. ${ }^{102}$

\section{Protease-activated Receptor Inhibitors}

Thrombin receptors PAR 1 and 4 mediate platelet activation and aggregation at low and high thrombin concentrations, respectively. PAR1 antagonists, such as vorapaxar, are potent antithrombotic agents, but significantly increase bleeding. ${ }^{103}$ Parmodulins are a new class of PAR1 antagonists in development which exhibit antithrombotic effects in animal models without affecting hemostasis. ${ }^{104}$ The PAR4 antagonist BMS-986120 has similar antithrombotic effects to clopidogrel, albeit with minimal effect on hemostasis ${ }^{105}$ and in a phase I study was shown to provide selective and reversible PAR4 antagonism and platelet aggregation. ${ }^{106}$ The PAR4 inhibitor BMS-986141 has been evaluated in a phase II clinical study for reduction of stroke recurrence (http:// www.clinicaltrials.gov. Unique identifier: NCT02671461).

\section{Protein Disulfide Isomerase Inhibitors}

Protein disulfide isomerase is required for thrombus formation, and inhibitors of this such as isoquercetin are being tested in phase II to III clinical trials of venous thrombosis in patients with cancer (http://www.clinicaltrials.gov. Unique identifier: NCT02195232).

\section{GP VI-collagen Inhibitors}

Binding of the platelet GP VI receptor to collagen leads to the release of soluble agonists and activation of GP IIb/IIla, resulting in platelet activation. A monoclonal antibody targeting the collagen-binding site of GP VI has in preclinical studies demonstrated antithrombotic effects without affecting hemostasis. ${ }^{107}$ Another monoclonal antibody against GP VI has recently been shown in a phase I study to achieve effective, dose-dependent inhibition of collagen-induced platelet aggregation without affecting hemostasis, ${ }^{108}$ and a phase II trial is planned in stroke (NCT03803007). Revacept, another anti-GP VI agent, has also been shown to effectively inhibit collagen-induced aggregation without increase in bleeding ${ }^{109}$ and is now being evaluated in phase II studies in coronary artery disease (http://www.clinicaltrials.gov. Unique identifiers: NCT03312855 a) and in symptomatic carotid stenosis (http://www.clinicaltrials.gov. Unique identifier: NCT01645306).

\section{Conclusion}

There have been tremendous advances in antiplatelet therapy for ACS and PCI, particularly in the last three decades. The initial excitement about the development of newer and more potent antiplatelet agents, which could reduce ischemic events, has led to an understanding of the importance of bleeding complications and given way to a desire to individualize and optimize treatment to also reduce bleeding risk. The future is also exciting. Ongoing studies focusing on personalizing treatment through the use of platelet function tests genetic testing, and by prolonging and intensifying or by shortening or de-escalating antiplatelet therapy will hopefully yield further insight into ways of optimizing antiplatelet therapy for the individual. Future antiplatelet therapy is likely to be more personalized, with a combination of individualized clinical risk assessment, incorporating perhaps both in vitro tests of thrombotic status as well as genomic studies may be necessary to provide the optimal patient profile to offer personalized antiplatelet therapy.

Conflict of Interest

T.G. reports personal fees from Astra Zeneca, Boehringer Ingelheim, Ferrer, and Pfizer, grants and personal fees 
from Bayer Healthcare, Bristol Myers Squibb, Daiichi Sankyo, and Eli Lilly, outside the submitted work.

\section{References}

1 Davies MJ. The birth, growth and consequences of the atherosclerotic plaque. Dialogues Cardiovasc Med 1999;4:115-178

2 Davies MJ. The pathophysiology of acute coronary syndromes. Heart 2000;83(03):361-366

3 Moscucci M, Fox KAA, Cannon CP, et al. Predictors of major bleeding in acute coronary syndromes: the Global Registry of Acute Coronary Events (GRACE). Eur Heart J 2003;24(20):1815-1823

4 Segev A, Strauss BH, Tan M, Constance C, Langer A, Goodman SG; Canadian Acute Coronary Syndromes Registries Investigators. Predictors and 1-year outcome of major bleeding in patients with non-ST-elevation acute coronary syndromes: insights from the Canadian Acute Coronary Syndrome Registries. Am Heart J 2005;150(04):690-694

5 Yeh RW, Secemsky EA, Kereiakes DJ, et al; DAPT Study Investigators. Development and validation of a prediction rule for benefit and harm of dual antiplatelet therapy beyond 1 year after percutaneous coronary intervention. JAMA 2016;315(16):1735-1749

6 Costa F, van Klaveren D, James S, et al; PRECISE-DAPT Study Investigators. Derivation and validation of the predicting bleeding complications in patients undergoing stent implantation and subsequent dual antiplatelet therapy (PRECISE-DAPT) score: a pooled analysis of individual-patient datasets from clinical trials. Lancet 2017;389(10073):1025-1034

7 Abu-Assi E, Raposeiras-Roubin S, Cobas-Paz R, et al. Assessing the performance of the PRECISE-DAPT and PARIS risk scores for predicting one-year out-of-hospital bleeding in acute coronary syndrome patients. EuroIntervention 2018;13(16):1914-1922

8 Urban P, Mehran R, Colleran R, et al. Defining high bleeding risk in patients undergoing percutaneous coronary intervention. Circulation 2019;140(03):240-261

9 Randomised trial of intravenous streptokinase, oral aspirin, both, or neither among 17,187 cases of suspected acute myocardial infarction: ISIS-2. ISIS-2 (Second International Study of Infarct Survival) Collaborative Group. Lancet 1988;2 (8607):349-360

10 Collaboration A; Antithrombotic Trialists' Collaboration. Collaborative meta-analysis of randomised trials of antiplatelet therapy for prevention of death, myocardial infarction, and stroke in high risk patients. BMJ 2002;324(7329):71-86

11 Ibanez B, James S, Agewall S, et al; ESC Scientific Document Group. 2017 ESC Guidelines for the management of acute myocardial infarction in patients presenting with ST-segment elevation: the task force for the management of acute myocardial infarction in patients presenting with ST-segment elevation of the European Society of Cardiology (ESC). Eur Heart J 2018;39 (02):119-177

12 Roffi M, Patrono C, Collet J-PP, et al; ESC Scientific Document Group. 2015 ESC Guidelines for the management of acute coronary syndromes in patients presenting without persistent STsegment elevation: task force for the management of acute coronary syndromes in patients presenting without persistent ST-Segment Elevation of the European Society of Cardiology (ESC). Eur Heart J 2016;37(03):267-315

13 Yusuf S, Zhao F, Mehta SR, Chrolavicius S, Tognoni G, Fox KK; Clopidogrel in Unstable Angina to Prevent Recurrent Events Trial Investigators. Effects of clopidogrel in addition to aspirin in patients with acute coronary syndromes without ST-segment elevation. N Engl J Med 2001;345(07):494-502

14 Leon MB, Baim DS, Popma JJ, et al; Stent Anticoagulation Restenosis Study Investigators. A clinical trial comparing three antithrombotic-drug regimens after coronary-artery stenting. N Engl J Med 1998;339(23):1665-1671
15 Wiviott SD, Braunwald E, McCabe CH, et al; TRITON-TIMI 38 Investigators. Prasugrel versus clopidogrel in patients with acute coronary syndromes. N Engl J Med 2007;357(20):2001-2015

16 Wallentin L, Becker RC, Budaj A, et al; PLATO Investigators. Ticagrelor versus clopidogrel in patients with acute coronary syndromes. N Engl J Med 2009;361(11):1045-1057

17 Sibbing D, Angiolillo DJ, Huber K. Antithrombotic therapy for acute coronary syndrome: past, present and future. Thromb Haemost 2017;117(07):1240-1248

18 Velders MA, Abtan J, Angiolillo DJ, et al; PLATO Investigators. Safety and efficacy of ticagrelor and clopidogrel in primary percutaneous coronary intervention. Heart 2016;102(08): 617-625

19 Schüpke S, Neumann F-JJ, Menichelli M, et al; ISAR-REACT 5 Trial Investigators. Ticagrelor or prasugrel in patients with acute coronary syndromes. N Engl J Med 2019;381(16):1524-1534

$20 \mathrm{Hamm}$ CW, Heeschen C, Goldmann B, et al. Benefit of abciximab in patients with refractory unstable angina in relation to serum troponin T levels. c7E3 Fab antiplatelet therapy in unstable refractory angina (CAPTURE) study investigators. N Engl J Med 1999;340(21):1623-1629

21 Platelet Receptor Inhibition in Ischemic Syndrome Management in Patients Limited by Unstable Signs and Symptoms (PRISMPLUS) Study Investigators. Inhibition of the platelet glycoprotein IIb/IIIa receptor with tirofiban in unstable angina and non-Qwave myocardial infarction. N Engl J Med 1998;338(21): 1488-1497

22 Platelet Glycoprotein IIb/IIIa in Unstable Angina: Receptor Suppression Using Integrilin Therapy (PURSUIT) Trial Investigators. Inhibition of platelet glycoprotein IIb/IIIa with eptifibatide in patients with acute coronary syndromes. N Engl J Med 1998;339 (07):436-443

23 D’Ascenzo F, Bollati M, Clementi F, et al. Incidence and predictors of coronary stent thrombosis: evidence from an international collaborative meta-analysis including 30 studies, 221,066 patients, and 4276 thromboses. Int J Cardiol 2013;167(02): 575-584

24 Stone GW, Witzenbichler B, Guagliumi G, et al; HORIZONS-AMI Trial Investigators. Bivalirudin during primary $\mathrm{PCI}$ in acute myocardial infarction. N Engl J Med 2008;358(21):2218-2230

25 Dangas G, Aymong ED, Mehran R, et al; CADILLAC Investigators. Predictors of and outcomes of early thrombosis following balloon angioplasty versus primary stenting in acute myocardial infarction and usefulness of abciximab (the CADILLAC trial). Am J Cardiol 2004;94(08):983-988

26 Sweeny JM, Gorog DA, Fuster V. Antiplatelet drug 'resistance'. Part 1: mechanisms and clinical measurements. Nat Rev Cardiol 2009;6(04):273-282

27 Gorog DA, Sweeny JM, Fuster V. Antiplatelet drug 'resistance'. Part 2: laboratory resistance to antiplatelet drugs-fact or artifact? Nat Rev Cardiol 2009;6(05):365-373

28 Hochholzer W, Trenk D, Bestehorn H-PP, et al. Impact of the degree of peri-interventional platelet inhibition after loading with clopidogrel on early clinical outcome of elective coronary stent placement. J Am Coll Cardiol 2006;48(09):1742-1750

29 Geisler T, Zürn C, Simonenko R, et al. Early but not late stent thrombosis is influenced by residual platelet aggregation in patients undergoing coronary interventions. Eur Heart J 2010; 31(01):59-66

30 Morel O, El Ghannudi S, Jesel L, et al. Cardiovascular mortality in chronic kidney disease patients undergoing percutaneous coronary intervention is mainly related to impaired P2Y12 inhibition by clopidogrel. J Am Coll Cardiol 2011;57(04):399-408

31 Cuisset T, Frere C, Quilici J, et al. Relationship between aspirin and clopidogrel responses in acute coronary syndrome and clinical predictors of non response. Thromb Res 2009;123(04): 597-603 
32 Frere C, Cuisset T, Quilici J, et al. ADP-induced platelet aggregation and platelet reactivity index VASP are good predictive markers for clinical outcomes in non-ST elevation acute coronary syndrome. Thromb Haemost 2007;98(04):838-843

33 Alexopoulos D, Xenogiannis I, Vlachakis P, Tantry U, Gurbel PA. Peri-procedural platelet reactivity in percutaneous coronary intervention. Thromb Haemost 2018;118(07):1131-1140

34 de Carvalho LP, Fong A, Troughton R, et al. Prognostic implications of dual platelet reactivity testing in acute coronary syndrome. Thromb Haemost 2018;118(02):415-426

35 Winter M-PP, Grove EL, De Caterina R, et al. Advocating cardiovascular precision medicine with P2Y12 receptor inhibitors. Eur Heart J Cardiovasc Pharmacother 2017;3(04):221-234

36 Shuldiner AR, O'Connell JR, Bliden KP, et al. Association of cytochrome P4502C19 genotype with the antiplatelet effect and clinical efficacy of clopidogrel therapy. JAMA 2009;302(08):849-857

37 Mega JL, Close SL, Wiviott SD, et al. Cytochrome p-450 polymorphisms and response to clopidogrel. N Engl J Med 2009;360 (04):354-362

38 Simon T, Verstuyft C, Mary-Krause M, et al; French Registry of Acute ST-Elevation and Non-ST-Elevation Myocardial Infarction (FAST-MI) Investigators. Genetic determinants of response to clopidogrel and cardiovascular events. N Engl J Med 2009;360 (04):363-375

39 Mega JL, Simon T, Collet J-PP, et al. Reduced-function CYP2C19 genotype and risk of adverse clinical outcomes among patients treated with clopidogrel predominantly for PCI: a meta-analysis. JAMA 2010;304(16):1821-1830

40 Holmes MV, Perel P, Shah T, Hingorani AD, Casas JP. CYP2C19 genotype, clopidogrel metabolism, platelet function, and cardiovascular events: a systematic review and meta-analysis. JAMA 2011;306(24):2704-2714

41 Sorich M, Rowlan A, McKinnon R, et al. CYP2C19 genotype has a greater effect on adverse cardiovascular outcomes following PCI and in Asian populations treated with clopidogrel: a metaanalysis. Circ Cardiovasc Genet 2014;7:895-902

42 Frére C, Cuisset T, Gaborit B, Alessi MC, Hulot JS. The CYP2C19*17 allele is associated with better platelet response to clopidogrel in patients admitted for non-ST acute coronary syndrome. J Thromb Haemost 2009;7(08):1409-1411

43 Sorich MJ, Vitry A, Ward MB, Horowitz JD, McKinnon RA. Prasugrel vs. clopidogrel for cytochrome P450 2C19-genotyped subgroups: integration of the TRITON-TIMI 38 trial data. J Thromb Haemost 2010;8(08):1678-1684

44 Wallentin L, James S, Storey RF, et al; PLATO investigators. Effect of CYP2C19 and ABCB1 single nucleotide polymorphisms on outcomes of treatment with ticagrelor versus clopidogrel for acute coronary syndromes: a genetic substudy of the PLATO trial. Lancet 2010;376(9749):1320-1328

45 Claassens DMF, Vos GJA, Bergmeijer TO, et al. A genotype-guided strategy for Oral $\mathrm{P}_{2} \mathrm{Y}_{12}$ inhibitors in primary PCI. N Engl J Med 2019;381(17):1621-1631

46 Price MJ, Berger PB, Teirstein PS, et al; GRAVITAS Investigators. Standard- vs high-dose clopidogrel based on platelet function testing after percutaneous coronary intervention: the GRAVITAS randomized trial. JAMA 2011;305(11):1097-1105

47 Trenk D, Stone GW, Gawaz M, et al. A randomized trial of prasugrel versus clopidogrel in patients with high platelet reactivity on clopidogrel after elective percutaneous coronary intervention with implantation of drug-eluting stents: results of the TRIGGER-PCI (Testing Platelet Reactivity In Patients Undergoing Elective Stent Placement on Clopidogrel to Guide Alternative Therapy With Prasugrel) study. J Am Coll Cardiol 2012;59(24): 2159-2164

48 Collet J-PP, Cuisset T, Rangé G, et al; ARCTIC Investigators. Bedside monitoring to adjust antiplatelet therapy for coronary stenting. N Engl J Med 2012;367(22):2100-2109
49 Cayla G, Cuisset T, Silvain J, et al; ANTARCTIC investigators. Platelet function monitoring to adjust antiplatelet therapy in elderly patients stented for an acute coronary syndrome (ANTARCTIC): an open-label, blinded-endpoint, randomised controlled superiority trial. Lancet 2016;388(10055):2015-2022

50 Gorog DA, Fuster V. Platelet function tests in clinical cardiology: unfulfilled expectations. J Am Coll Cardiol 2013;61(21): 2115-2129

51 Flierl U, Zauner F, Sieweke J-TT, et al. Efficacy of prasugrel administration immediately after percutaneous coronary intervention in ST-elevation myocardial infarction. Thromb Haemost 2017;117(01):99-104

52 Bhatt DL, Stone GW, Mahaffey KW, et al; CHAMPION PHOENIX Investigators. Effect of platelet inhibition with cangrelor during PCI on ischemic events. N Engl J Med 2013;368(14):1303-1313

53 Droppa M, Vaduganathan M, Venkateswaran RV, et al. Cangrelor in cardiogenic shock and after cardiopulmonary resuscitation: a global, multicenter, matched pair analysis with oral $\mathrm{P}_{12}$ inhibition from the IABP-SHOCK II trial. Resuscitation 2019; 137:205-212

54 Silvain J, Storey RF, Cayla G, et al. P2Y12 receptor inhibition and effect of morphine in patients undergoing primary PCI for STsegment elevation myocardial infarction. The PRIVATE-ATLANTIC study. Thromb Haemost 2016;116(02):369-378

55 Bellandi B, Zocchi C, Xanthopoulou I, et al. Morphine use and myocardial reperfusion in patients with acute myocardial infarction treated with primary PCI. Int J Cardiol 2016;221:567-571

56 Kubica J, Adamski P, Ostrowska M, et al. Morphine delays and attenuates ticagrelor exposure and action in patients with myocardial infarction: the randomized, double-blind, placebocontrolled IMPRESSION trial. Eur Heart J 2016;37(03):245-252

57 Duerschmied D, Bode C. Life-saving therapy versus symptom relief: anti-platelet agents and opioids in coronary intervention. Thromb Haemost 2018;118(08):1350-1351

58 Ibrahim K, Shah R, Goli RR, et al. Fentanyl delays the platelet inhibition effects of oral ticagrelor: full report of the PACIFY randomized clinical trial. Thromb Haemost 2018;118(08):1409-1418

59 Parodi G, Valenti R, Bellandi B, et al. Comparison of prasugrel and ticagrelor loading doses in ST-segment elevation myocardial infarction patients: RAPID (rapid activity of platelet inhibitor drugs) primary PCI study. J Am Coll Cardiol 2013;61(15):1601-1606

60 Parodi G, Bellandi B, Xanthopoulou I, et al. Morphine is associated with a delayed activity of oral antiplatelet agents in patients with ST-elevation acute myocardial infarction undergoing primary percutaneous coronary intervention. Circ Cardiovasc Interv 2014;8(01):e001593

61 Nimmo WS, Heading RC, Wilson J, Tothill P, Prescott LF. Inhibition of gastric emptying and drug absorption by narcotic analgesics. Br J Clin Pharmacol 1975;2(06):509-513

62 Thomas MR, Morton AC, Hossain R, et al. Morphine delays the onset of action of prasugrel in patients with prior history of STelevation myocardial infarction. Thromb Haemost 2016;116 (01):96-102

63 McCarthy CP, Bhambhani V, Pomerantsev E, Wasfy JH. In-hospital outcomes in invasively managed acute myocardial infarction patients who receive morphine. J Interv Cardiol 2018;31(02): 150-158

64 Puymirat E, Lamhaut L, Bonnet N, et al. Correlates of pre-hospital morphine use in ST-elevation myocardial infarction patients and its association with in-hospital outcomes and long-term mortality: the FAST-MI (French Registry of Acute ST-elevation and non-ST-elevation Myocardial Infarction) programme. Eur Heart J 2016;37(13):1063-1071

65 Farag M, Spinthakis N, Srinivasan M, Sullivan K, Wellsted D, Gorog DA. Morphine analgesia pre-PPCI is associated with prothrombotic state, reduced spontaneous reperfusion and greater infarct size. Thromb Haemost 2018;118(03):601-612 
66 de Waha S, Eitel I, Desch S, et al. Intravenous morphine administration and reperfusion success in ST-elevation myocardial infarction: insights from cardiac magnetic resonance imaging. Clin Res Cardiol 2015;104(09):727-734

67 Bonin M, Mewton N, Roubille F, et al; CIRCUS Study Investigators. Effect and safety of morphine use in acute anterior ST-segment elevation myocardial infarction. J Am Heart Assoc 2018;7(04): e006833

68 Lapostolle F, Van't Hof AW, Hamm CW, et al; ATLANTIC Investigators. Morphine and ticagrelor interaction in primary percutaneous coronary intervention in st-segment elevation myocardial infarction: ATLANTIC-morphine. Am J Cardiovasc Drugs 2019;19(02):173-183

69 Spinthakis N, Gue Y, Farag M, et al. Apixaban enhances endogenous fibrinolysis in patients with atrial fibrillation. Europace 2019;21(09):1297-1306

70 Sikora J, Niezgoda P, Barańska M, et al. METoclopramide administration as a strategy to overcome morphine-ticagrelor interaction in patients with unstable Angina pectorIS-the METAMORPHOSIS trial. Thromb Haemost 2018;118(12): 2126-2133

71 Rollini F, Franchi F, Hu J, et al. Crushed prasugrel tablets in patients with STEMI undergoing primary percutaneous coronary intervention: the CRUSH study. J Am Coll Cardiol 2016;67 (17):1994-2004

72 Parodi G, Xanthopoulou I, Bellandi B, et al. Ticagrelor crushed tablets administration in STEMI patients: the MOJITO study. J Am Coll Cardiol 2015;65(05):511-512

73 Asher E, Frydman S, Katz M, et al; For The PLATIS (Platelets and Thrombosis in Sheba) Study Group. Chewing versus swallowing ticagrelor to accelerate platelet inhibition in acute coronary syndrome - the CHEERS study. Thromb Haemost 2017;117 (04):727-733

74 Giannopoulos G, Deftereos S, Kolokathis F, Xanthopoulou I, Lekakis J, Alexopoulos D. P2Y12 receptor antagonists and morphine: a dangerous liaison? Circ Cardiovasc Interv 2016;9(09): e004229

75 Kubica J, Kubica A, Jilma B, et al. Impact of morphine on antiplatelet effects of oral P2Y12 receptor inhibitors. Int J Cardiol 2016;215:201-208

76 Bonaca MP, Bhatt DL, Cohen M, et al; PEGASUS-TIMI 54 Steering Committee and Investigators. Long-term use of ticagrelor in patients with prior myocardial infarction. N Engl J Med 2015; 372(19):1791-1800

77 Vranckx P, Valgimigli M, Jüni P, et al; GLOBAL LEADERS Investigators. Ticagrelor plus aspirin for 1 month, followed by ticagrelor monotherapy for 23 months vs aspirin plus clopidogrel or ticagrelor for 12 months, followed by aspirin monotherapy for 12 months after implantation of a drug-eluting stent: a multicentre, open-label, randomised superiority trial. Lancet 2018; 392(10151):940-949

78 Feres F, Costa RA, Abizaid A, et al; OPTIMIZE Trial Investigators. Three vs twelve months of dual antiplatelet therapy after zotarolimus-eluting stents: the OPTIMIZE randomized trial. JAMA 2013;310(23):2510-2522

79 Kim B-KK, Hong M-KK, Shin D-HH, et al; RESET Investigators. A new strategy for discontinuation of dual antiplatelet therapy: the RESET Trial (REal safety and efficacy of 3-month dual antiplatelet therapy following endeavor zotarolimus-eluting stent implantation). J Am Coll Cardiol 2012;60(15):1340-1348

80 Urban P, Meredith IT, Abizaid A, et al; LEADERS FREE Investigators. Polymer-free drug-coated coronary stents in patients at high bleeding risk. N Engl J Med 2015;373(21):2038-2047

81 Varenne O, Cook S, Sideris G, et al; SENIOR investigators. Drugeluting stents in elderly patients with coronary artery disease (SENIOR): a randomised single-blind trial. Lancet 2018;391 (10115):41-50
82 Yin S-H-LH, Xu P, Wang B, et al. Duration of dual antiplatelet therapy after percutaneous coronary intervention with drugeluting stent: systematic review and network meta-analysis. BMJ 2019;365:12222

83 Cuisset T, Deharo P, Quilici J, et al. Benefit of switching dual antiplatelet therapy after acute coronary syndrome: the TOPIC (timing of platelet inhibition after acute coronary syndrome) randomized study. Eur Heart J 2017;38(41):3070-3078

84 Sibbing D, Aradi D, Jacobshagen C, et al; TROPICAL-ACS Investigators. Guided de-escalation of antiplatelet treatment in patients with acute coronary syndrome undergoing percutaneous coronary intervention (TROPICAL-ACS): a randomised, open-label, multicentre trial. Lancet 2017;390 (10104):1747-1757

85 Hein R, Gross L, Aradi D, et al; Collaborators. Diabetes and outcomes following guided de-escalation of antiplatelet treatment in acute coronary syndrome patients undergoing percutaneous coronary intervention: a pre-specified analysis from the randomised TROPICAL-ACS trial. EuroIntervention 2019;15(06): e513-e521

86 Gross L, Trenk D, Jacobshagen C, et al. Genotype-phenotype association and impact on outcomes following guided De-escalation of anti-platelet treatment in acute coronary syndrome patients: the TROPICAL-ACS genotyping substudy. Thromb Haemost 2018;118(09):1656-1667

87 Watanabe H, Domei T, Morimoto T, et al; STOPDAPT-2 Investigators. Effect of 1-month dual antiplatelet therapy followed by clopidogrel vs 12-month dual antiplatelet therapy on cardiovascular and bleeding events in patients receiving PCI: the STOPDAPT-2 randomized clinical trial. JAMA 2019;321(24): 2414-2427

88 Hahn J-YY, Song YB, Oh J-HH, et al; SMART-CHOICE Investigators. Effect of P2Y12 inhibitor monotherapy vs dual antiplatelet therapy on cardiovascular events in patients undergoing percutaneous coronary intervention: the SMART-CHOICE randomized clinical trial. JAMA 2019;321(24):2428-2437

89 Hahn J-Y, Song YB, Oh J-H, et al; SMART-DATE investigators. 6month versus 12 -month or longer dual antiplatelet therapy after percutaneous coronary intervention in patients with acute coronary syndrome (SMART-DATE): a randomised, open-label, non-inferiority trial. Lancet 2018;391(10127):1274-1284

90 Gimbel ME. Randomised comparison of clopidogrel versus ticagrelor or prasugrel in patients of 70 years or older with non-STelevation acute coronary syndrome - POPular AGE. European Society of Cardiology 2019. Available at: https://www.acc.org/ latest-in-cardiology/clinical-trials/2019/08/30/09/59/popularage. Accessed Februray 3, 2020

91 Mehran R, Baber U, Sharma SK, et al. Ticagrelor with or without aspirin in high-risk patients after PCI. N Engl J Med 2019;381 (21):2032-2042

92 Delesque-Touchard N, Pflieger AM, Bonnet-Lignon S, et al. SAR216471, an alternative to the use of currently available $\mathrm{P}_{2} \mathrm{Y}_{12}$ receptor inhibitors? Thromb Res 2014;134(03): 693-703

93 Storey RF, Gurbel PA, ten Berg J, et al. Pharmacodynamics, pharmacokinetics, and safety of single-dose subcutaneous administration of selatogrel, a novel P2Y12 receptor antagonist, in patients with chronic coronary syndromes. Eur Heart J 2019. Doi: 10.1093/eurheartj/ehz807

94 Wong P, Crain E, Watson C, et al. Differential effects of P2Y1 versus P2Y12 receptor antagonism on thrombosis and bleeding in rabbits. Eur Heart J 2013;34:1431-P1431

95 Gremmel T, Yanachkov IB, Yanachkova MI, et al. Synergistic inhibition of both P2Y1 and P2Y12 adenosine diphosphate receptors as novel approach to Rapidly attenuate platelet-mediated thrombosis. Arterioscler Thromb Vasc Biol 2016;36(03): 501-509 
96 Li J, Vootukuri S, Shang Y, et al. RUC-4: a novel $\alpha$ IIb $\beta 3$ antagonist for prehospital therapy of myocardial infarction. Arterioscler Thromb Vasc Biol 2014;34(10):2321-2329

97 Schwarz M, Meade G, Stoll P, et al. Conformation-specific blockade of the integrin GPIIb/IIIa: a novel antiplatelet strategy that selectively targets activated platelets. Circ Res 2006;99(01): 25-33

98 McFadyen JD, Schaff M, Peter K. Current and future antiplatelet therapies: emphasis on preserving haemostasis. Nat Rev Cardiol 2018;15(03):181-191

99 Markus HS, McCollum C, Imray C, Goulder MA, Gilbert J, King A. The von Willebrand inhibitor ARC1779 reduces cerebral embolization after carotid endarterectomy: a randomized trial. Stroke 2011;42(08):2149-2153

100 Bartunek J, Barbato E, Heyndrickx G, Vanderheyden M, Wijns W, Holz JB. Novel antiplatelet agents: ALX-0081, a Nanobody directed towards von Willebrand factor. J Cardiovasc Transl Res 2013;6 (03):355-363

101 Lei X, Reheman A, Hou Y, et al. Anfibatide, a novel GPIb complex antagonist, inhibits platelet adhesion and thrombus formation in vitro and in vivo in murine models of thrombosis. Thromb Haemost 2014;111(02):279-289

102 Nylander S, Wågberg F, Andersson M, Skärby T, Gustafsson D. Exploration of efficacy and bleeding with combined phosphoinositide 3-kinase $\beta$ inhibition and aspirin in man. J Thromb Haemost 2015;13(08):1494-1502
103 Morrow DA, Braunwald E, Bonaca MP, et al; TRA 2P-TIMI 50 Steering Committee and Investigators. Vorapaxar in the secondary prevention of atherothrombotic events. N Engl J Med 2012;366(15):1404-1413

104 Aisiku O, Peters CG, De Ceunynck K, et al. Parmodulins inhibit thrombus formation without inducing endothelial injury caused by vorapaxar. Blood 2015;125(12):1976-1985

105 Wong PC, Seiffert D, Bird JE, et al. Blockade of protease-activated receptor-4 (PAR4) provides robust antithrombotic activity with low bleeding. Sci Transl Med 2017;9(371):eaaf5294

106 Wilson SJ, Ismat FA, Wang Z, et al. PAR4 (protease-activated receptor 4) antagonism with BMS-986120 inhibits human ex vivo thrombus formation. Arterioscler Thromb Vasc Biol 2018;38 (02):448-456

107 Ohlmann P, Hechler B, Ravanat C, et al. Ex vivo inhibition of thrombus formation by an anti-glycoprotein VI Fab fragment in non-human primates without modification of glycoprotein $\mathrm{VI}$ expression. J Thromb Haemost 2008;6(06):1003-1011

108 Voors-Pette C, Lebozec K, Dogterom P, et al. Safety and tolerability, pharmacokinetics, and pharmacodynamics of ACT017, an antiplatelet GPVI (glycoprotein VI) Fab. Arterioscler Thromb Vasc Biol 2019;39(05):956-964

109 Ungerer M, Rosport K, Bültmann A, et al. Novel antiplatelet drug revacept (Dimeric Glycoprotein VI-Fc) specifically and efficiently inhibited collagen-induced platelet aggregation without affecting general hemostasis in humans. Circulation 2011;123(17):1891-1899 